\title{
Ethos in Sports: \\ An Aristotelian Examination Focused on Source Credibility and the Modern Day Athlete
}

\author{
Andrew DIX ${ }^{1}$
}

The current study analyzed source credibility in a sports related to highlight the central findings focused on the dimensions of competence, goodwill, and trustworthiness. Quantitative methods were then utilized as a means to empirically test whether unconfirmed reports of performanceenhancing drug use could negatively impact perceptions of athlete ethos. Findings revealed that athletes who were inconclusively linked to performanceenhancers were evaluated less favorably in terms of their overall competence, goodwill, and trustworthiness. The implications from this study indicate that clean athletes who are wrongfully accused should proactively communicate their innocence to the general public. Athletes who are not clean should employ various face and image restoration strategies in order to effectively manage their public credibility. Study limitations and directions for future research were appropriately addressed within the present scholarship.

Keywords: sports, ethos, Aristotle, communication, perception

${ }^{1}$ Department of Communication Studies and Organizational Communication, Middle Tennessee State University, Murfreesboro, TN, USA 


\section{Introduction}

It was Aristotle (translated in 1932) who notably declared: "we must consider any incidental state that makes the characters of men vary" (p. 58). The aforementioned Greek philosopher who authored The Rhetoric prominently defined ethos as an instrument of persuasion that centered on the character of another individual (Aristotle, 1932). It is safe to say that the Aristotelian conceptualization of ethos has fascinated social science scholars as classic research has broadly contrasted how Isocrates and Aristotle categorized source credibility (Benoit, 1984), succinctly revealed that perceptions of teacher credibility were positively correlated with student perceptions of student learning (Teven \& McCroskey, 1997), and conspicuously detailed methods for altering the ethos or credibility of a source (Andersen \& Clevenger Jr., 1963). Indeed, the afore referenced investigations have captivated modern day academics. However, examining the notion of ethos in newer and less conventional contexts could yield novel data surrounding this notable social construct.

The present study analyzed whether perceptions of athlete ethos were susceptible to negative messages within a sports related framework. A review of previous literature was completed in order to understand the multi-dimensional construct of ethos as well as highlight germane sports scholarship. A withinsubject design was accordingly employed in order to compare and contrast the ethos sub-dimensions of competence, goodwill, and trustworthiness. Study findings were then dissected within a practical framework and avenues for future research were identified. In essence, the primary focus of the current research was to examine the interconnectedness of athlete ethos and negative messages involving performance-enhancing drugs.

\section{Literature Review}

Contemporary scholarship has proposed that ethos is comprised of three dimensions that include competence, goodwill, and trustworthiness (McCroskey \& Teven, 1999). Sports research on the dimension of competence by Allen and Howe (1998) revealed that positive praise from coaches resulted in female athletes reporting higher levels of self-perceived competence. Ryska (2002) utilized a sample of high school athletes and suggested that: "the quality of an adolescent's sport experience may have a pervasive impact on his or her competence perceptions outside the sport realm" (p. 123). Similar research by Ridgers, Fazey, and Fairclough (2007) encouraged physical educators: "to explore ways in which perceived athletic competence can be developed, particularly for girls" (p. 346). While the majority of sports literature focused on competence and 
perceptions has highlighted methods for improving self-perception, the extant scholarship devoted to the other two dimensions of ethos is also noteworthy.

Sports literature that specifically analyzes the construct of goodwill has been heavily focused on perceptions. Dees, Bennett, and Villegas (2008) reported that casual sports fans could be transformed into avid sports fans if perceptions of goodwill were more readily apparent. Intercollegiate athletics scholarship by Ott (2011) proposed that athletic departments could increase faculty perceptions of goodwill by supporting outreach endeavors that promoted more social interaction amongst faculty and athletic personnel. Similar intercollegiate sports scholarship by Chung (2013) that focused on undergraduate applications indicated that: "the carryover rate of athletic goodwill is evident only for students with low SAT scores, suggesting that students with low ability value the historical success of intercollegiate athletics over longer periods of time" (p. 696). Put another way, it seems that perceptions of goodwill for college athletic programs are more salient amongst lowering scoring SAT college applicants relative to higher scoring SAT college applicants (Chung, 2013). When taken together, it appears that goodwill perceptions are a relatively fluid variable that is potentially impacted by peripheral constructs.

The third dimension of ethos that is germane to the present investigation is the notion of trustworthiness. A sports study by Anderson, Miles, Robinson, and Mahoney (2004) that examined athlete perceptions highlighted that trustworthiness was a characteristic that athletes valued in their sports psychologists. Sports research by Mazer, Barnes, Grevious, and Boger (2013) reported that verbally aggressive coaches were perceived as less trustworthy than coaches who used an affirming style of communication. Holmes, McNeil, and Adorna (2010) sample of college student athletes revealed that male athletes perceived trustworthiness as a more valuable asset for team leaders to possess relative to their female athlete counterparts. Although it is important to consider specific perceptions related to the three dimensions of ethos, it is also imperative to broadly address general perception in sport.

Previous literature that focuses on the relationship between perception and sport can be categorized as fragmented. Classic scholarship courtesy of Comisky, Bryant, and Zillman (1977) indicated that broadcaster commentary influenced participant perceptions of athletes who were professional hockey players. Nonverbal literature by Frank and Gilovich (1988) revealed that referees perceived athletes whose jersey color were primarily black as more aggressive and likely to commit a penalty than athletes whose primary jersey color was not black. That noted, a robust amount of extant literature has supported the stereotype that we perceive the modern day athlete as a big dumb jock 
who possesses limited intellectual ability (Coakely, 2004; Sailes, 1996; Simons, Bosworth, Fujita, \& Jensen, 2007). In short, it appears that society validates the efforts of the modern day athlete but nevertheless maintains critical perceptions of some athletes outside of the field of play.

An additional variable of interest that has received a robust amount of attention from researchers who focus on sports and perception has looked at athletes who are linked to performance enhancing substances. For instance, research by Paccagnella and Grove (1997) revealed that: "steroid users were seen as significantly less honest and rule oriented than those convicted of criminal acts" (p. 185). A more specialized investigation by Engelberg, Moston, and Skinner (2012) indicated that the majority of the general public believed that sports teams should be penalized if members of their club were linked to performance-enhancing drugs. Moreover, scholarship by Soldberg, Hanstad, and Thoring (2010) suggested that public opinion favored: "strict reactions from sponsors towards athletes and sports involved in doping” (p. 197). All things considered, it appears the average sports consumer has limited tolerance for athletes who are associated with performance-enhancing measures.

\section{The Current Research}

The present study was designed to analyze whether perceptions of athlete ethos were vulnerable to allegations of performance-enhancing drug use that were publicly communicated. Scholarship has indicated that ethos is comprised of three dimensions that include competence, goodwill, and trustworthiness (McCroskey \& Teven, 1999). Previous literature has illustrated that perceptions of competence shared a negative relationship with verbal aggressiveness (Cole \& McCroskey, 2003) and nonverbal disagreement (Seiter, 1999). Other perceptual research by Horan and Chory (2011) revealed that perceptions of goodwill decreased for employees who dated their supervisor. It should also be noted that perceptions of trustworthiness decreased in circumstances where inappropriate or misbehavior occurred (Thweatt \& McCroskey, 1998). Sports literature has revealed that the general public is critical of individuals who use performanceenhancers (Paccagnella \& Grove, 1997). All of the aforementioned studies as a collective whole provide reason to believe that claims of performance-enhancing drug use will result in athletes being perceived as less credible. Thus, the following hypotheses are being proposed:

H1: Perceptions of athlete competence will decrease after allegations of performance-enhancing drug use come to light. 
H2: Perceptions of athlete goodwill will decrease after allegations of performance-enhancing drug use come to light.

H3: Perceptions of athlete trustworthiness will decrease after allegations of performance-enhancing drug use come to light.

Previous scholarship devoted to perceptions and sports has revealed noteworthy insight on the consumers of sport. Extant literature has revealed that the general public is rather critical of athletes and entities who are in any way associated with performance-enhancing substances (e.g. Engelberg, Moston, \& Skinner, 2012; Paccagnella \& Grove, 1997; Soldberg, Hanstad, \& Thoring, 2010). At the same time, previous scholarship has not sufficiently scratched the surface with regard to parceling out whether different ethnicities maintain different ethos perceptions of athletes who reportedly foray with performanceenhancers. Therefore, the following research question is being put forth:

RQ1: What effect will participant race have on perceptions of the competence, goodwill, and trustworthiness of an athlete who allegedly used performance-enhancing drugs?

\section{Method}

\section{Participants}

One hundred and nine $(N=109)$ undergraduate students served as the participants in this study. Females $(N=62)$ accounted for $56.9 \%$ of the sample while males $(N=47)$ represented $43.1 \%$ of the sample. The median age of study participants was 19.6 years of age $(s d=3.20)$. Caucasian participants were the most represented ethnicity in this investigation at $62.4 \%$ followed by African Americans (26.6\%), Asian Americans (6.4\%), Hispanic Americans (2.8\%), and Indian Americans (1.8\%). Extra course credit was awarded to the participants in this study.

\section{Instrumentation}

A modified version of the source credibility measurement scale of McCroskey and Teven (1999) served as the main instrument in this investigation. The measure featured a 7 -point response continuum in which scores ranged from strongly disagree (1) up to strongly agree (7). The source credibility measure was comprised of three separate sub-scales that measured perceptions of competence, goodwill, and trustworthiness. Reliability analyses for the aforementioned subscales yielded a Cronbach's Alpha of .80 for the competence sub-scale, a score 
of .75 for the goodwill sub-scale, and .82 for trustworthiness sub-scale. In sum, a reliable instrument was utilized in the present investigation.

\section{Procedures}

The procedural element of this study was comprised of eight different components. First, a headshot photograph of an anonymous white male athlete was selected for this study. Second, a racializer TM application morphed the headshot photograph of the anonymous white male athlete into that of a black male athlete; the racializing process created a second headshot photograph of a black male athlete that (besides skin tone color) was identical to the original headshot photograph of the white male athlete. Third, participants completed a pre-test measure that assessed their perceptions of the source credibility (McCroskey \& Teven, 1999) of the headshot photograph of the black male athlete and then completed a separate pre-test measure that assessed their perceptions of the source credibility (McCroskey \& Teven, 1999) of the original headshot photograph of the white male athlete. Fourth, participants engaged in an unrelated distraction task. Fifth, participants were informed that the black male athlete and the white male athlete had allegedly used performance-enhancing drugs; the allegations were identical for both races and participants were made completely aware that the allegations had never been proven true. Sixth, participants completed a post-test measure that re-assessed their perceptions of the source credibility (McCroskey \& Teven, 1999) of the headshot photograph of the black male athlete and then completed a separate post-test measure that re-assessed their perceptions of the source credibility (McCroskey \& Teven, 1999) of the original headshot photograph of the white male athlete. Seventh, a manipulation measure was administered to participants in order to determine whether study participants viewed the mere allegations of performance-enhancing drug use in a negative light.

\section{Results}

\section{Preliminary Analysis}

The first statistical analysis that was completed before testing began on the main hypotheses and research question was a manipulation check. This measure was administered to participants as a means to determine whether they perceived the allegations of performance-enhancing drug use as more negative or positive in nature. The 7-point Likert scale for the manipulation measure had responses that varied from 1 (strongly disagree) up to 7 (strongly agree). The results of a paired-samples $t$ test indicated that participants saw a significant difference between the performance-enhancing drug allegations being perceived 
as negative as opposed to the performance-enhancing drug allegations negative being perceived as positive $(t(107)=22.397, p<.001)$. The mean for the allegations being perceived as negative was $5.85(s d=1.27)$ whereas the mean for the allegations being perceived as positive was $1.72(s d=.89)$. These results indicate that participants viewed the supplied allegations of performanceenhancing drug use in a negative capacity.

\section{Main Analyses}

Hypothesis one proposed that perceptions of athlete competence would decrease after allegations of performance enhancing drug use came to light. The results of a repeated measures ANOVA uncovered support for this hypothesis ( $F$ $(1,107)=28.638, p<.001$, Partial Eta Squared $=.210)$. Pre-test perceptions of the competence of an athlete before allegations of performance-enhancing drug use emerged were $4.32(s d=0.70)$ on a 7-point response continuum while post-test perceptions of the competence of an athlete after allegations of performanceenhancing drug use emerged were $3.67(s d=1.06)$ on a 7-point response continuum. Therefore, it can be argued that mere allegations of performanceenhancing drug use are enough to make an athlete appear less competent.

Hypothesis two suggested that perceptions of athlete goodwill would decrease after allegations of performance-enhancing drug use came to light. Support was found for this hypothesis after the completion of a repeated measures ANOVA $(F(1,106)=13.683, p<.001$, Partial Eta Squared $=.113)$. It was before allegations of performance-enhancing drug use emerged that pretest perceptions of athlete goodwill were $4.21(s d=0.55)$ on a 7-point response continuum while it was after allegations of performance-enhancing drug use emerged that post-test perceptions of athlete goodwill were $3.90(s d=0.75)$ on a 7-point response continuum. Indeed, unconfirmed reports of an athlete using performance-enhancing drugs results in an athlete being perceived as lacking in goodwill.

Hypothesis three posited that perceptions of athlete trustworthiness would decrease after allegations of performance-enhancing drug use came to light. A repeated measures ANOVA uncovered support this hypothesis ( $F(1$, $107)=98.306, p<.001$, Partial Eta Squared $=.477)$. Initial perceptions of the trustworthiness of an athlete before allegations of performance-enhancing drug use were publicly disseminated were $4.30(s d=0.68)$ on a 7 -point response continuum whereas post-test perceptions of the trustworthiness of an athlete after allegations of performance-enhancing drug use surfaced were 2.61 ( $s d$ $=1.45$ ). Put simply, athletes who have allegedly used performance-enhancing drugs are seen as less trustworthy. 
The research question for this study asked: What effect will participant race have on perceptions of the competence, goodwill, and trustworthiness of an athlete who allegedly used performance-enhancing drugs? Study participants were coded as either members of the majority ethnic group (e.g. Caucasian American) or members of a minority ethnic group (e.g. African American, Asian American, Hispanic American, and Indian American) in order to test the proposed research question. A series of $2 \times 2$ mixed factorial ANOVAs were individually completed in which participant race (majority ethnic group or minority ethnic group) was entered as the between subjects factor and administration (pre-test or post-test) was entered as the within subjects factor for each of the three separate dimensions of ethos. Results on the perceptions of trustworthiness variable revealed evidence of a two-way interaction ( $F$ (1, 106) $=3.938, p=.05$, Partial Eta Squared $=.035)$ between participant race and administration (see figure one on the following page). Members of the majority ethnic group rated the trustworthiness of an athlete during the pre-test at 4.33 $(s d=0.72)$ while members of the majority ethnic group rated the trustworthiness of an athlete at $2.38(s d=1.32)$ during the post-test administration. In contrast, members of minority ethic groups rated the trustworthiness of an athlete during the pre-test at $4.26(s d=0.61)$ while members of minority ethnic groups rated the trustworthiness of an athlete at $3.00(s d=1.59)$ during the post-test administration. That noted, a statistically significant interaction was not observed for the perceptions of competence variable $(F(1,106)=1.615, p=.20$, Partial Eta Squared $=.015)$ and was not observed for the perceptions of goodwill variable $(F(1,105)=.976, p=.325$, Partial Eta Squared $=.009)$ after the completion of two separate $2 \times 2$ mixed factorial ANOVAs for those dimensions of ethos. In short, the main finding of the proposed research question was that: Caucasian Americans were more critical of the trustworthiness of athletes who allegedly used performance-enhancing drugs relative to individuals who do not identify themselves as Caucasian Americans. 


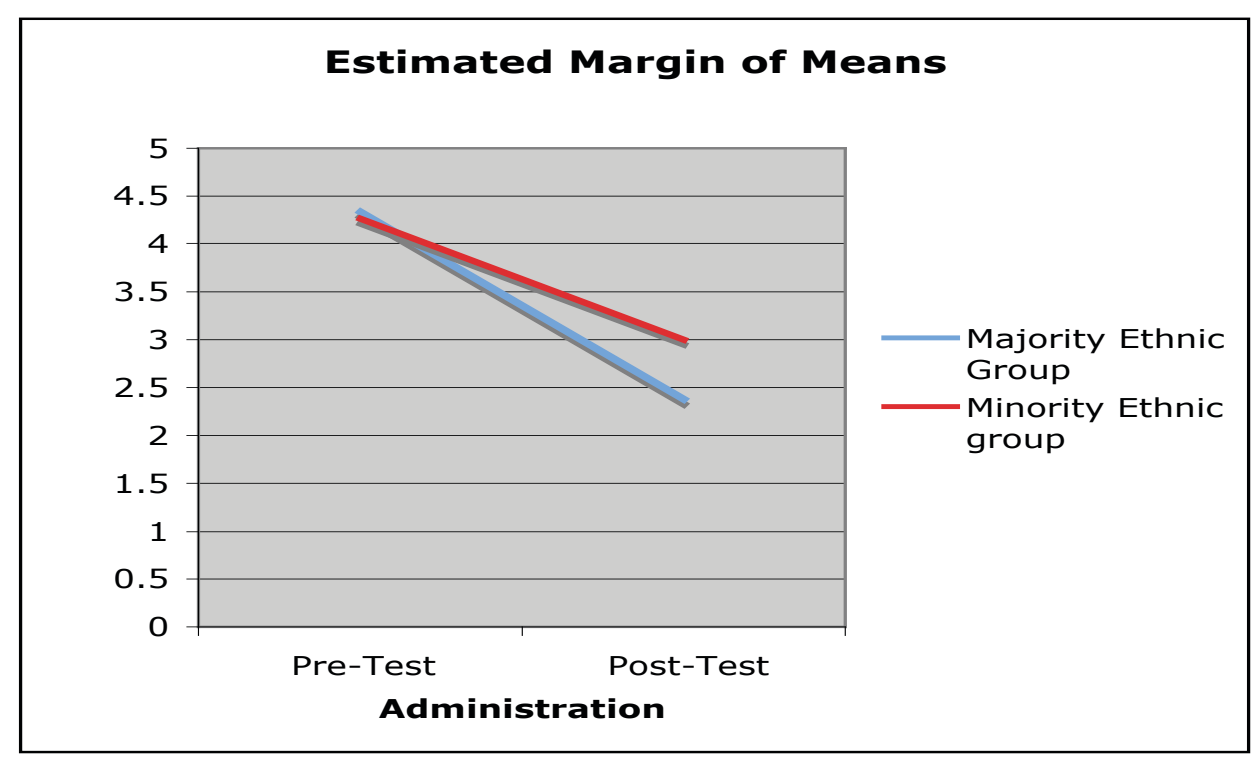

Figure 1. Two-Way Interaction Plot between Participant Race and Administration on Perceptions of Trustworthiness

\section{Discussion}

The current study focused on the credibility of athletes who were inconclusively associated with performance-enhancing drugs. The ethos dimensions of competence, goodwill, and trustworthiness were measured with the McCroskey and Teven (1999) source credibility measure. Findings indicated that all ethos perceptions decreased after claims of performance-enhancing drug use came to light. The present research also revealed that study participants who were in a minority ethnic group (e.g. African Americans, Asian Americans, Hispanic Americans, and Indian Americans) were less judgmental of the trustworthiness of athletes who allegedly used performance-enhancing drugs relative to the study participants who were in the majority ethnic group (e.g. Caucasian Americans). There are four points of discussion that emerged from this investigation that require additional discussion.

The first noteworthy finding was that perceptions of competence decreased after athletes were allegedly linked to performance-enhancers. This finding suggests that individuals hastily jump to the conclusion that allegations of performance-enhancing drug use which are levied against athletes are in fact true 
despite not being confirmed. It also suggests that initial impressions of athletic competence are not necessarily lasting impressions of athletic competence. It is imperative that athletes who are falsely accused of performance-enhancing drugs use get in front of the performance-enhancing drug story as a means to take control of the narrative. Image restoration theory hints that the strategy of simple denial would be appropriate if the accused athlete is innocent (Benoit, 1997). An athlete who is unjustly associated with performance-enhancing drugs may want to consider taking a professionally administered drug test in order to quickly dispel the notion that the athlete used performance-enhancing drugs as a means to supplement her or his apparent lack of competence within the field of play. A professionally administered drug test that reveals the athlete was not using performance-enhancers could be released via credible media outlets to help control public opinion and illustrate that the athlete is naturally competent. In contrast, the athlete who has been rightfully accused of experimented with performance enhancing drugs should according to image restoration theory employ a mortification strategy in which she or he admits wrongdoing and asks for forgiveness (Benoit, 1997). The strategy of simple denial or mortification would thereby empower the athlete and perpetuate an efficient means to either maintain or set the foundation for re-establishing her or his athletic competence in the eyes of the general public.

The second noteworthy point of discussion that emerged from the present study was the finding that perceptions of goodwill decreased after allegations of performance-enhancing drug use came to light. Athletes are commonly perceived as ambassadors of goodwill. An athlete who is allegedly linked to performanceenhancers violates the general perception of being an individual who is concerned about the interests of others. The findings from this study implicitly suggest that mere allegations of performance-enhancing drug use result in athletes being perceived as self-centered, which is not consistent with promoting the goodwill of others. The act of taking or allegedly taking performance-enhancing drugs could be conceptualized as either an individualistic or collectivistic act within the philosophical arena of goodwill. Some individuals may perceive athletes who are allegedly linked to performance-enhancers as selfish individuals who utilize sordid measures to achieve personal and athletic benefits. On the other hand, it is possible that some individuals may perceive athletes who are allegedly linked to performance-enhancers as non-selfish individuals who reportedly use performance-enhancers in an effort to perform at a high level on the field as a means to effectively benefit the best collective interests of the team as a collective whole. It appears that the previous explanation as opposed to the latter is a more plausible reason for why this particular result emerged because the participants in this study were from the predominantly individualistic culture that is the United States. Nevertheless, the data from this study does not allow such a claim 
to be made with confidence. Put differently, the perceived intentions (whether individualistic or collectivistic) of an athlete who supposedly experiments with performance-enhancing drugs may potentially mediate how that athlete is seen in terms of goodwill. The perceived intentionality of athletes may have affected the observed effect size for the perceptions of goodwill variable for athletes who allegedly used performance-enhancing drugs in this study being that goodwill was the least robust of the three dimensions of ethos. Perhaps in that regard the finding that athletes who are allegedly linked to performance enhancers are perceived as having less goodwill brings about more questions than answers. Nevertheless, the results of this investigation suggest that athletes who are associated with performance-enhancers are not regarded as individuals who promote goodwill.

A third point of discussion that should be unpacked was the finding that athletes who had an alleged foray with performance-enhancing drugs were seen as less trustworthy. It should be noted that the observed effect size for the perceptions of trustworthiness variable was the most sizeable of the three dimensions of ethos. Two of the Likert items that centered on perceptions of trustworthiness for this study specifically focused on the principles of morality and ethics. The reason why the observed effect size was so large is perhaps tied to high profile American athletes (e.g. Lance Armstrong, Mark McGwire, etc.) who have been associated with performance-enhancers. High profile athletes in the media who are linked to performance-enhancers often publicly maintain their innocence with regard to taking performance-enhancing drugs during their professional athletic career only to later confess after the conclusion of their professional athletic career that they had in fact utilizing performance-enhancers during their professional athletic career. Said athletes were probably seen as less trustworthy upon later admitting to their performance-enhancing transgressions and admitting to their overt verbal deception in order to conceal their use of performance-enhancing substances. The admission of performance-enhancing drug use among notable and highly publicized athletes may lead some individuals to unfairly assume that less notable athletes (and perhaps all athletes who are allegedly linked to performance-enhancing drug use) will lie about performanceenhancers until they either get definitively caught or feel a strong intrinsic desire to come clean. Regardless, public denials by high profile athletes who have dabbled with performance-enhancers limits their trustworthiness and has a trickle down effect on how trustworthy we deem less well known athletes who are accused of using performance-enhancing drugs. In other words, it seems that we stereotype all athletes who are associated with performance-enhancing drugs as untrustworthy based on how untrustworthy we perceived various mainstream athletes who have admitted to using performance-enhancing drugs. 
Perhaps most individuals expect accused athletes to deny, lie, and later admit to using performance-enhancers based on our current method of sense-making.

A final piece of discussion that should be highlighted was the finding that Caucasian American participants evaluated the trustworthiness of an athlete who alleged used performance-enhancing drugs more harshly than individuals who did not identify themselves as members of the majority ethnic group (e.g. African Americans, Asian Americans, Hispanic Americans, and Indian Americans). While pre-test perceptions of trustworthiness for members of the majority ethnic group (pre-test mean $=4.33$ ) and members of minority ethnic groups (pre-test mean $=4.26$ ) were relatively similar, the post-test differences in terms of trustworthiness perceptions for the two groups were notably marked as post-test perceptions of trustworthiness for the majority ethnic group (posttest mean $=2.38$ ) were moderately lower than the post-test perceptions of trustworthiness for members who were in minority ethnic groups (post-test mean $=3.00)$ after allegations of performance-enhancing drug use were brought to light. Philosophical narratives that are ethnically rooted can potentially explain this finding. Previous scholarship by Marsiglia, Kulis, and Hecht (2001) indicated that non-Caucasian American adolescents used a greater variety of drugs and used hard drugs with a greater frequency in comparison to Caucasian American adolescents. Some of the participants in this study who were not Caucasian Americans were perhaps socialized into a minority culture that previous literature (e.g. Hecht, Trost, Bator, \& MacKinnon, 1997; Marsiglia, Kulis, \& Hecht, 2001; Moon, Hecht, Jackson, \& Spellers, 1999) illustrates as having a more open view of drug use or at least less judgmental views of drug use. This phenomenon appears to be applicable to perceptions of performance-enhancing drugs as well. Put differently, members of minority groups are more sympathetic and sensitive to athletes who are reportedly linked to performance-enhancing drugs because their social culture maintains different philosophical views about drug use behavior and drug attitudes relative to Caucasian Americans. It could also be argued that individuals who are not in the majority ethnic group see performance-enhancing drugs as a gray area in terms of right and wrong in the world of sports. After all, not all performance-enhancing drugs are illegal substances with regard to federal and international law. Perhaps a foul such as allegedly using performance-enhancing drugs is only a foul in the field of trustworthiness if the referee or an empowered official blows her or his whistle. All things considered, the overall results from this study suggest that unfavorable perceptions and allegations of performance-enhancing drug use are intertwined variables in the eyes of study participants regardless of their ethnicity. 


\section{Limitations and Future Research}

There are some limitations and directions for future research for the current investigation that deserve to be noted. One limitation of this investigation was that study participants only analyzed photographs of Caucasian American and African American athletes. Utilizing photographs of athletes from additional races and more athlete photographs in general would have benefited the present investigation. Another limitation that should be highlighted was that the data for this study was collected while the principal investigator was present. It is rather unlikely but possible that some of the study participants may have experienced experimenter effects during the post-test administration in which they may have consciously or unconsciously responded to scale items in a manner they believed to be consistent with what they thought the principal investigator was hoping to find. That noted, it was imperative that the principal investigator was present while data was being collected for the current research in order to assist with directions, questions, administration, and the like.

Future research into sports sciences should examine athletes who engage in alleged misbehavior autonomous of the field of play. For example, it would be interesting to see if elite athletes who are caught engaging in adulterous affairs are subsequently perceived by sports fans as being less competent or trustworthy. A separate avenue for future investigation could longitudinally examine whether unfavorable perceptions of athletes who transgress various moral lines ultimately subside over time. It would also be interesting to study whether above satisfactory performance on the field diminishes negative perceptions of athletes who violate socially acceptable behavior outside of the field of play. Scholarship that examines the possible interconnectedness of alleged off-field transgressions and on-field success has not been sufficiently explored and for many sports researchers it would represent a whole new ballgame. 


\section{References}

Allen, J. B., \& Howe, B. L. (1998). Player ability, coach feedback, and female adolescent athletes' perceived competence and satisfaction. Journal of Sport and Exercise Psychology, 20, 280-299.

Andersen, K., \& Clevenger, Jr. (1963). A summary of experimental research in ethos. Speech Monographs, 30, 59-78. doi: 10.1080/03637756309375361

Anderson, A., Miles, A., Robinson, P., \& Mahoney, C. (2004). Evaluating the athlete's perception of the sport psychologist effectiveness: What should we be assessing? Psychology of Sport and Exercise, 5, 255-277. doi: 10.1016/S14690292(03)00005-0

Aristotle. (1932). The rhetoric of Aristotle: An expanded translation (L. Cooper, Trans.). New York, NY: Appleton.

Benoit, W. (1984, November). Isocrates, Aristotle, and credibility research. Paper presented at the annual meeting of the Speech Communication Association, Chicago, IL.

Benoit, W. (1997). Image repair discourse and crisis communication. Public Relations Review, 23, 177-186.

Chung, D. J. (2013). The dynamic advertising effect of collegiate athletics. Marketing Science, 32, 679-698. doi: http://dx.doi.org/10.1287/mksc.2013.0795

Coakley, J. (2004). Sport in Society: Issues and Controversies (8th ed.). Boston, MA: McGraw-Hill.

Cole, J.G., \& McCroskey, J.C. (2003). The association of perceived communication apprehension, shyness, and verbal aggression with perceptions of source credibility and affect in organizational and interpersonal contexts. Communication Quarterly, 51, 101-110.

Comisky, P., Bryant, J., \& Zillman, D. (1977). Commentary as a substitute for action. Journal of Communication, 27, 150-153. doi: 10.1111/j.1460-2466.1977. tb02141.x

Dees, W., Bennett, G., \& Villegas, J. (2008). Measuring the effectiveness of an elite intercollegiate football program. Sport Marketing Quarterly, 17, 79-89 
Engelberg, T., Moston, S., \& Skinner, J. (2012). Public perception of sport antidoping policy in Australia. Drugs: Education, Prevention \& Policy, 19, 84-87. doi: 10.3109/09687637.2011.590556

Frank, M. G., \& Gilovich, T. (1988). The dark side of self- and social perception: Black uniforms and aggression in professional sports. Journal of Personality and Social Psychology, 54, 74-85. doi: 10.1037//0022-3514.54.1.74

Hecht, M., Trost, M. R., Bator, R. J., \& MacKinnon, D. (1997). Ethnicity and sex similarities and differences in drug resistance. Journal of Applied Communication Research, 25, 75-97.

Holmes, R. M., McNeil, M., \& Adorna, P. (2010). Student athletes' perceptions of formal and informal team leaders. Journal of Sport Behavior, 33, 442-465

Horan, S. M., \& Chory, R. M. (2011). Understanding work/life blending: Credibility implications for those who date at work. Communication Studies, 62, 563580. doi: 10.1080/10510974.2011.582663

Kassing,J.W.,\&Infante,D.A.(1999).Aggressivecommunicationinthecoach-athlete relationship. Communication Research Reports, 16, 110-120. doi: $10.1080 / 08824099909388708$

Marsiglia, F., Kulis, S., \& Hecht, M. L. (2001). Ethnic labels and ethnic identity as predictors of drug use among middle school students in the southwest. Journal of Research on Adolescence, 11, 21-48.

Mazer, J. P., Barnes, K., Grevious, A., \& Boger, C. (2013). Coach verbal aggression: A case study examining effects of athlete motivation and perceptions of coach credibility. International Journal of Sport Communication, 6, 203-213

McCroskey, J. C., \& Teven, J. J. (1999). Goodwill: A reexamination of the construct and its measurement. Communication Monographs, 66, 90-103. doi: $10.1080 / 03637759909376464$

Moon, D. G., Hecht, M. L., Jackson, K. M., \& Spellers, R. E. (1999). Ethnic and gender differences and similarities in adolescent drug use and refusals of drug offers. Substance Use \& Misuse, 34, 1059-1083.

Ott, M. (2011). Faculty satisfaction with intercollegiate athletics. Journal of Issues in Intercollegiate Athletics, 4, 370-395. 
Paccagnella, M., \& Grove, J.R. (1997). Drugs, sex, and crime in sport: An Australian perspective. Journal of Sport \& Social Issues, 21, 179-188. doi: $10.1177 / 019372397021002005$

Ridgers, N. D., Fazey, D. M., \& Fairclough, S. J. (2007). Perceptions of athletic competence and fear of negative evaluation during physical education. British Journal of Educational Psychology, 77, 339-349.

Ryska, T. A. (2002). The effects of athletic identity and motivation goals on global competence perceptions of student-athletes. Child Study Journal, 32, 109-129.

Sailes, G. A. (1996). An investigation of campus stereotypes: The myth of black athletic superiority and the dumb jock stereotype. In R.E. Lapchick (Ed.), Sport in Society: Equal opportunity or business as usual? (pp. 193-202). Thousand Oaks, CA: Sage.

Seiter, J. S. (1999). Does communicating nonverbal disagreement during an opponent's speech affect the credibility of the debater in the background? Psychological Reports, 84, 855-861. doi: 10.2466/pr0.1999.84.3.855

Simons, H. D., Bosworth, C., Fujita, S., \& Jensen, M. (2007). The athlete stigma in higher education. College Student Journal, 41, 251-273.

Soldberg, H. A., Hanstad, D. V., \& Thoring, T. A. (2010). Doping in elite sport - do the fans care? Public opinion on the consequences of doping scandals. International Journal of Sports Marketing and Sponsorship, 11, 185-199.

Teven, J. J., \& McCroskey, J. C. (1997). The relationship of perceived teacher caring with student learning and teacher evaluation. Communication Education, 46, 1-9. doi: 10.1080/03634529709379069

Thweatt, K.S., \& McCroskey, J.C. (1998). The impact of teacher immediacy and misbehaviors on teacher credibility. Communication Education, 47, 348-358. doi: 10.1080/03634529809379141 
Andrew DIX, Ph.D. is currently an instructor of communication studies at Middle Tennessee State University in Murfreesboro, TN (USA) where he has been teaching for the last four years. He earned his Ph.D. in communication studies from the University of Southern Mississippi in 2012. His research examines interpersonal relationships. The intersection of sports and communication is a specific area of interest for him. His previous research endeavors have examined the communicative behaviors of professional athletes and he is currently investigating whether nonverbal criterion can influence whether females athletes are perceived as more or less aggressive within the field of play. He is a member of the Communication and Sport division of the National Communication Association.

\section{Corresponding address:}

Andrew Dix

Department of Communication Studies and Organizational Communication

Middle Tennessee State University

Jones Hall 361

MTSU Box 200

1301 E. Main Street

Murfreesboro, TN 37132-0001

Phone: (615) 898-2275

E-mail: andrew.dix@mtsu.edu 
